Revue

Revue de l'histoire des religions

del'histoire des religions

$1 \mid 2017$

Varia

Franz-Xaver Bischof et Sylvio De FRANCESCHI (éd.), Histoires antiromaines II. L'antiromanisme dans l'historiographie ecclésiastique catholique ( $\mathrm{XVI}^{\mathrm{e}}$ $X X^{e}$ siècles). Actes de la journée d'études de Munich (13 septembre 2012)

Lyon, RESEA-LARHRA («Chrétiens et sociétés », 23), 2014

Lorenzo Comensoli Antonini

OpenEdition

Édition électronique

URL : http://journals.openedition.org/rhr/8707

DOI : $10.4000 /$ rhr.8707

ISSN : 2105-2573

Éditeur

Armand Colin

Édition imprimée

Date de publication : 1 mars 2017

Pagination : 183-185

ISBN : 978-2-200-93125-4

ISSN : 0035-1423

Référence électronique

Lorenzo Comensoli Antonini, « Franz-Xaver Bischof et Sylvio De Franceschi (éd.), Histoires antiromaines II. L'antiromanisme dans l'historiographie ecclésiastique catholique ( $x v l^{e}-x x^{e}$ siècles). Actes de la journée d'études de Munich (13 septembre 2012) ", Revue de l'histoire des religions [En ligne], 1 | 2017, mis en ligne le 24 mars 2017, consulté le 08 janvier 2021. URL : http://journals.openedition.org/rhr/8707 ; DOI : https://doi.org/10.4000/rhr.8707

Ce document a été généré automatiquement le 8 janvier 2021

Tous droits réservés 


\section{Franz-Xaver Bischof et Sylvio DE FRANCESCHI (éd.), Histoires}

antiromaines II. L'antiromanisme dans

l'historiographie ecclésiastique catholique (XVI $-\mathrm{XX}^{e}$ siècles). Actes de la journée d'études de Munich

\section{(13 septembre 2012)}

Lyon, RESEA-LARHRA (« Chrétiens et sociétés », 23), 2014

Lorenzo Comensoli Antonini

\section{RÉFÉRENCE}

Franz-Xaver BISCHOF et Sylvio DE FRANCESCHI (éd.), Histoires antiromaines II.

L'antiromanisme dans l'historiographie ecclésiastique catholique (XVI ${ }^{e}-\mathrm{XX}{ }^{e}$ siècles). Actes de la journée d'études de Munich (13 septembre 2012), Lyon, RESEA-LARHRA (« Chrétiens et sociétés », 23), 2014

1 Regroupant les actes d'une deuxième journée d'études dédiée à l'historiographie antiromaine qui s'est déroulée à Munich le 13 septembre 2012, le recueil est consacré aux auteurs qui ont contesté la papauté romaine sans pour autant refuser la communion avec Rome. Les sujets traités couvrent la période comprise entre le $\mathrm{xVI}^{\mathrm{e}}$ et le $\mathrm{XIX}^{\mathrm{e}}$ siècle et l'exposition suit un ordre chronologique. Le dessein général des contributions - explicité par Sylvio De Franceschi en introduction - est de montrer comment les historiens antiromains ont contribué, mieux que les partisans de Rome, à 
la naissance d'une histoire ecclésiastique critique, en adoptant une méthode de recherche libérée des intérêts apologétiques et édifiants.

2 Les propositions dédiées à des sujets français - la grande majorité - mettent en lumière le lien étroit existant entre antiromanisme et gallicanisme. Le premier essai reconstitue l'affaire Jean Tanquerel, un étudiant en théologie de la Sorbonne qui en 1561 soutint une thèse défendant le droit pontifical à destituer les princes. Pierre-Jean Souriac montre comment l'histoire de sa condamnation par le Parlement de Paris fut passée sous silence jusqu'à la fin du $\mathrm{XVI}^{\mathrm{e}}$ siècle, après que le roi français eut été excommunié. Par la suite, à partir du milieu des années 1610, l'érudition historique a transformé l'affaire Tanquerel en "un événement majeur de l'histoire de l'Église de France " (p. 27), repris par toute l'historiographie française successive comme un symbole des libertés gallicanes. De la même manière, l'antiromanisme du traité inédit (1653) de Louis Machon, analysé par Frédéric Gabriel, est fortement lié à la défense des prérogatives royales et de l'autonomie du pouvoir des États séculiers. Pour Machon, la papauté s'est corrompue à partir du moment où elle a commencé à se considérer comme "héritière souveraine et temporelle d'une grandeur impériale» (p.103), en trahissant ainsi l'essence de son autorité apostolique, puisque d'après Lorenzo Valla «Papa tantum vicarius Christi sit, et non etiam Caesaris » (ibid.). Le trait gallican caractérise aussi l'attitude envers la hiérarchie romaine des Mémoires de Montlosier (1826), objet du chapitre rédigé par Sylvain Milbach. Ses antagonistes principaux sont les jésuites et l'ultramontanisme, à cause de leur soutien aux prétentions de Rome sur le pouvoir des États. Par un "effet de miroir » (p. 167), Lamennais dénonce dans les mêmes années «les usages politiques du religieux» (ibid.) et, de ce fait, il exalte le pouvoir spirituel des papes, universel et non dépendant de la fragile contingence des pouvoirs temporels. Ce débat reprend des éléments de la doctrine gallicane classique, mais la différence décisive est que « la question religieuse est désormais indissociable du choc révolutionnaire » (p. 169); il s'agit donc de repenser la place de la religion dans la société contemporaine. Dans le même esprit d'un gallicanisme actualisé, Lucien Lacroix écrit en 1904 la Vie de Mgr. Landriot. Jean-François Landriot avait reconnu le Syllabus comme une aveugle déclaration de guerre à la modernité et il avait ensuite participé au concile Vatican I en tant qu'archevêque de Reims, en faisant partie de la minorité vaincue par le parti infaillibiliste. L'auteur de la contribution, Christian Sorel, note comment les deux prélats partagent la même «ambition de réconciliation de l'Église catholique et de la société moderne » (p. 240), en dénonçant la personnalisation du pouvoir pontifical comme la plaie principale du catholicisme.

3 Chez les antiromains, la rigueur historiographique devient une arme pour contester la hiérarchie curiale. Au cours de la première journée d'études à Lyon en septembre 2010, Bernard Hours avait présenté l'Histoire ecclésiastique, parue entre 1690 et 1738 . Il se focalise ici sur la querelle autour de l'Histoire des années 1726-1737, qui se jouait sur des disputes historiques. Cette œuvre est principalement accusée de réduire « l'autorité du pape à celle des évêques » (p. 135), à travers la négation opérée par Claude Fleury - et fondée sur des remarques historico-philologiques - de l'authenticité historique des décrétales pseudo-isidoriennes du $\mathrm{IX}^{\mathrm{e}}$ siècle. À l'inverse, ses défenseurs répondaient en soulignant l'existence au sein de l'Église d'un courant réformiste mettant en question le pouvoir absolu des papes depuis le XII ${ }^{\mathrm{e}}$ siècle. La contestation des dérives absolutistes de la papauté n'est donc pas une opinion hérétique, puisque les doctrines ecclésiologiques alternatives au modèle centraliste romain appartiennent à juste titre à l'histoire de 
l'Église catholique. Sylvio De Franceschi analyse ensuite l'Histoire de l'Église de France de René-François Guettée (1847-1856). Il affirme que le propos de Guettée, même après la condamnation de l'Index, était moins d'attaquer la papauté, que d'écrire une histoire selon une méthode objective et non apologétique. "Guettée reste intimement tributaire du discours tenu par les Lumières » (p.190) et il est inspiré par des historiens libéraux comme Michelet et Guizot, bien qu'il soit lui aussi profondément lié au gallicanisme, duquel il hérite la sévérité «à l'égard du système politique mis en place au Moyen Âge » dans l'Église (p. 182).

En dehors de la France, l'antiromanisme peut assumer des traits plus inattendus, comme dans le cas étudié par Paolo Broggio dans l'Historia pontifical y católica, dont la première édition par Gonzalo de Illescas date de 1565 . Tout en célébrant le pouvoir absolu et universel des papes, elle décrit par contre l'histoire de l'Église comme une vie désormais entrée dans la vieillesse et corrompue par le pouvoir temporel. La chrétienté - après avoir perdu l'hégémonie dans le Vieux monde à cause du schisme protestant peut seulement être sauvée par la monarchie espagnole qui, bien plus que Rome, est l'agent sotériologique auquel Dieu a conféré le rôle de défenseur de la vraie foi et la mission d'évangéliser l'Amérique. En proposant des arguments plus traditionnels, Le Pape et le Concile (1869) de Janus, pseudonyme de l'historien allemand catholique Ignaz von Döllinger, reflète selon Franz-Xaver Bischof «le conflit entre deux courants théologiques et ecclésiologiques irréconciliables» (p. 224): les catholiques, qui acceptaient la présence au sein du corps ecclésial d'un pluralisme d'opinions, et l'ultramontanisme, qui avec la proclamation du dogme de l'infaillibilité papale en 1870 s'imposait comme l'unique modèle ecclésiologique légitime.

5 En général, l'ensemble des contributions identifie le trait commun de l'antiromanisme moderne dans la lutte contre l'absolutisme papal et sa volonté de soumettre chaque aspect de la vie du corps ecclésial au contrôle de Rome. Sur le plan historiographique, l'apport majeur du recueil réside dans l'explication du rôle d'avant-garde des historiens ecclésiastiques antiromains dans l'adoption d'une méthode scientifique en raison de leur nécessité de rapporter l'absolutisme papal à un tournant historique funeste, contrairement aux arguments théologiques et scripturaux des papistes qui considéraient la potestas absoluta du souverain pontife comme une indéniable vérité de la foi. En ce qui concerne l'édition, au soin typographique impeccable, on apprécie le choix de compléter les essais par des annexes qui offrent au lecteur la voix originelle des textes. En conclusion, s'il faut indiquer une lacune de l'ouvrage, on dira que le fait d'avoir limité l'arc chronologique des études au début du xxe siècle ne permet pas de constater le rôle central joué au concile Vatican II par les idées ecclésiales contraires à l'absolutisme papal. Pendant le concile, l'idée du pontife comme roi absolu et toutpuissant de l'Église a été abandonnée en faveur d'une considération positive du pluralisme qui anime le corps ecclésial. Ce résultat a coïncidé avec la réhabilitation implicite de l'héritage de la tradition antiromaine. 


\section{AUTEURS}

\section{LORENZO COMENSOLI ANTONINI}

Università degli Studi, Padova - Université Paris-Sorbonne. 